\title{
The Reasons Young Children Give to Peers When Explaining Their Judgments of Moral and Conventional Rules
}

Article in Developmental Psychology · October 2017

DOI: $10.1037 / \operatorname{dev} 0000424$

\section{CITATIONS}

0

3 authors, including:
READS

106

\section{Maria Mammen}

Max Planck Institute for Evolutionary Anthropo..

4 PUBLICATIONS 9 CITATIONS

SEE PROFILE
Bahar Köymen

Max Planck Institute for Evolutionary Anthropo... 21 PUBLICATIONS 86 CITATIONS

SEE PROFILE 
The reasons young children give to peers when explaining their judgments of moral and conventional rules

\author{
Maria Mammen $^{\mathrm{a}, \mathrm{b}}$, Bahar Köymen $^{\mathrm{b}}, \&$ Michael Tomasello ${ }^{\mathrm{a}, \mathrm{c}}$ \\ ${ }^{a}$ Max Planck Institute for Evolutionary Anthropology \\ ${ }^{b}$ University of Manchester \\ ${ }^{\mathrm{c}}$ Duke University
}

In Press at Developmental Psychology:

http://psycnet.apa.org/doi/10.1037/dev0000424

Acknowledgements: We would like to thank Gesa Volland, Pia Fischer, Martin Runge and Veronika Scheller for their help in recruiting the children and collecting the data; Nora Drewes and Lara Witzer for their help in reliability coding; Cristina Zickert and Marike Schreiber for the drawings and all nurseries and children for their friendly cooperation.

Correspondence concerning this article should be addressed to Maria Mammen, Max Planck Institute for Evolutionary Anthropology, Department of Developmental and Comparative Psychology, Deutscher Platz 6, D-04103, Leipzig, Germany. E-mail: maria_mammen@eva.mpg.de 


\begin{abstract}
Moral justifications work, when they do, by invoking values that are shared in the common ground of the interlocutors. 3- and 5-year-old peer dyads ( $N=144)$ were asked to identify and punish norm transgressors. In the moral condition, the transgressor violated a moral norm (e.g., by stealing); in the social rules condition, she/he violated a context-specific rule (e.g., by placing a yellow toy in a green box, instead of a yellow box). Children in both age groups justified their punishment in the social rules condition mostly by referring to the rule (e.g., "He must put yellow toys in the yellow box"). In contrast, in the moral condition they mostly justified their punishment by simply referring to the observed fact (e.g., "He stole"), seeing no need to state the norm involved (e.g., "He must not steal."), presumably because they assumed this as part of their moral common ground with their partner. These results suggest that preschoolers assume certain common ground moral values with their peers and use these in formulating explicit moral judgments and justifications.
\end{abstract}

Keywords: moral common ground; reasoning; collaborative decision making; peer interactions 


\section{The reasons young children give to peers when explaining their judgments of moral and conventional rules}

In collaborative decision-making, people need to produce arguments to convince their partners (Mercier \& Sperber, 2011; Tomasello, 2014). To be convincing, speakers must structure their arguments according to the common ground that they share with their hearers. Toulmin's model of argumentation (1958) consists of three main components: a proposal/claim; a fact, which provides evidence for a proposal; and a warrant, which is the assumption that turns the fact into a justification. For example, two friends will have dinner. The host asks the guest to buy a cake. The guest says that she cannot and justifies this with a fact: "It's Sunday." This fact functions as a justification only if both speakers are aware of the warrant: "Bakeries are closed on Sundays." This warrant is part of their cultural common ground (Clark, 1996), the knowledge that members of a social group assume they share. Thus, such warrants do not have to be explained if speakers can safely assume this knowledge in their hearer.

In the preschool period, children begin to show sensitivity to their cultural common ground with others (Liebal, Carpenter, \& Tomasello, 2013). Using Toulmin's model of argumentation, Köymen, Rosenbaum, and Tomasello (2014; see also Köymen, Mammen, \& Tomasello, 2016) showed that preschoolers formulate their justifications differently depending on what they assume their partners know. 3- and 5-year-old peers were asked to build a zoo with items, which were conventional (e.g., toy animals) or unconventional (e.g., a ladder). For their proposals on conventional items (e.g., "Polar bears go there"), children used justifications that relied on implicit/unstated warrants (e.g., stating only the fact "There is ice", assuming that their partners know that polar bears live on ice). For unconventional items, however, they stated the warrants more often to create the necessary common ground (e.g., to justify the placement of the 
ladder next to monkeys, they stated, "That [:ladder] is for people. Animals don't come up this high... Only the monkeys", p.81).

An important part of cultural common ground is the social norms that govern a community. Numerous interview studies within the Domain Theory framework have shown that already preschool children distinguish between two types of social norms, namely moral norms and conventional norms, and display sensitivity to who should respect and follow what kinds of norms (Killen, 1991; Smetana, 2006; Turiel, 1983). These two kinds of social norms differ in two important aspects that are relevant to the current study: familiarity and severity. First, moral norms (e.g., "One should not steal") are familiar to almost everyone and it is easy to infer the reasons for their existence (e.g., "One should not steal because it harms others."). The familiarity of social conventional rules varies: Some social rules (e.g., "One must always put yellow toys in yellow boxes") might be familiar to only a small group of kindergarteners, while others (e.g., "One should not eat with one's hands") are familiar to a larger group of people. Nonetheless, conventional rules are somewhat idiosyncratic and the reasons for their existence are not easily inferred (do children know exactly why they should not eat with their hands?). Second, transgressions of moral norms are judged to be more severe and deserve more punishment than transgressions of social conventions. Several interview studies showed that already 3- to 4-yearolds differentiate between these two types of norms: They evaluate the norm violations by hypothetical characters in vignettes, and judge moral norm violations to be more severe and punishable than the violations of conventional norms (Davidson, Turiel, \& Black, 1983; Nucci \& Nucci, 1982; Smetana, 1981; Smetana \& Braeges, 1990).

Recent experimental studies have had children directly observe norm violations. A study by Schmidt, Rakoczy, and Tomasello (2012) showed that 3-year-olds understand that moral 
norms should be known and respected by more people: they protested both when in-group and out-group members violated a moral norm (e.g., destroying someone's property), whereas they protested only when an in-group, as opposed to an out-group member, violated a social conventional norm (e.g., playing a game incorrectly). Similarly, preschoolers take into account what common knowledge they have with their partners about context-specific game rules. Köymen, Schmidt, Rost, Lieven, and Tomasello (2015) had preschoolers play a sorting game with a peer, who either did not know the game or knew the game but played it incorrectly. When playing with a naïve partner, 3-year-olds used informative explanations (e.g., "One must put the flower with the flower", p. 99). However, when playing with a partner who knowingly violates the rule, children relied on their shared knowledge and used less informative explanations in their interventions (e.g., "No that goes here", p.99).

In all of these studies, preschool children intervened to a directly observed transgression ("No you should not do that") or simply answered the yes/no questions by the experimenter about the transgression (e.g., "Is it alright if X?") without necessarily justifying their normative judgments to a partner, unless asked by the experimenter. Justifying normative evaluations is a complex skill because to convince a partner about someone's wrongdoing, children need to formulate their explanations/justifications differently depending on how much common ground knowledge they can assume in their hearer about the transgression.

One context where children justify their normative judgments to convince an interlocutor is tattling: reporting a transgression by a third party to a second party to solicit agreement. Ingram and Berring (2010) observed naturalistic peer conflicts and found that 4-year-olds were more likely to tattle about moral transgressions, such as property entitlements and physical aggression (e.g., "He hurt me with the wheel", p.957), than disagreements within joint games 
(e.g., "She's not finished yet [with the paintbrush]; she won't hurry up", p.957), especially when they themselves were the victims of these transgressions. However, in such naturalistic studies there is no control over the kinds of transgressions and therefore no possible analysis of how their justifications differ depending on the transgressions. In an experimental study (Vaish, Missana, \& Tomasello, 2011), after witnessing a moral norm violation (e.g., destruction of an absent person's property), 3-year-olds tattled on the transgressor to the absent victim ("She tore up your beautiful flower", p.127). However, justifications were not specifically elicited or analyzed in this study.

In the current study, therefore, we investigated how 3- and 5-year-old children justified their normative evaluations to a peer. Each child in a dyad individually heard a different story. In the moral condition, the target child heard a story about a character violating a moral norm (e.g., by stealing), whereas in the social rules condition she heard a story about a character violating a context-specific rule (e.g., by eating cake with hands). In both conditions, the other child, the naïve child, heard a story about a neutral character. Then the children in the dyad were asked to decide together which character (the transgressor or the neutral character) should be awarded a marble. In both conditions the target child was the only one who knew about the transgressions so he/she had to explain to his/her partner in both conditions why a transgressor should not be awarded a marble. We predicted that children would punish the transgressor in both conditions regardless of the type of norm violation. However, due to the differences in familiarity and severity of the norm violations, we predicted that with their peers children would assume more "common ground" in their justifications in the moral condition than in the social rules condition. More specifically, we predicted that in the social rules condition, the target children would produce justifications in the form of warrants (e.g., explanations of the rule using normative 
language: "One should eat a cake with a fork") because context-specific rules are familiar to only a select group of people, as highlighted by Domain Theory (Killen, 1991; Smetana, 2006; Turiel, 1998). Without the warrants it is not completely clear why an act of "eating a cake with hands" deserves punishment, unless it is presented as an intentional act of breaking a social rule. On the other hand, we predicted that in the moral condition would mostly rely on facts (e.g., simple description of the action: "He stole") because the moral norms are familiar to everyone and part of children's cultural common ground. Further, the severity of a moral transgression does not depend on the context and is, thus, inherent in the action, even without reference to the underlying rule (e.g., no need to say, "One must not steal.”).

We also looked for potential age differences in 3-and 5-year-olds. It has been shown that even 3-year-olds distinguish between moral and social conventional transgressions (Nucci, \& Turiel, 1978; Smetana, \& Braeges, 1990) and can judge, in many cases, what is and is not in their cultural common ground with a novel interactant (Liebal et al., 2013). Moreover, between the age 3-4, children begin to understand that a person can be ignorant of a fact or a rule (e.g., Hogrefe, Wimmer, \& Perner, 1986; Wellman \& Lui, 2004). Furthermore, in previous studies (Köymen et al., 2014, 2016), 3-year-olds have been shown to be fairly good at adjusting the informativeness of their arguments depending on their inferences about their partner's knowledge and ignorance. However, 5-year-olds were much more consistent in deciding what is already known to their partner and providing relevant information to be convincing. 


\section{Methods}

\section{Participants}

The participants were 763 -year-olds $(M=3 ; 9$, range $=3 ; 6-3 ; 11 ; 38$ girls $)$ and 725 year-olds $(M=5 ; 9 ;$ range $=5 ; 6-5 ; 11 ; 36$ girls $)$ in same-age and same-sex dyads who knew each other. Two 3-year-old dyads were excluded from the analysis, because the target child did not answer any of the post-test questions correctly (see below). Each dyad was assigned randomly to one of the two experimental conditions. For each age group, there were 18 dyads ( 9 female) in each condition. All children were native German speakers from different socio-economic backgrounds.

\section{Materials}

At the warm-up, the dyads were presented with two drawings of two characters, one of which would get a marble (see Appendix A for all story books and their narration). There were six picture books about six different characters, 4 girls and 2 boys, for the experimental trials. Three books depicted transgressions and the other three books neutral actions. Each book consisted of three drawings.

\section{Procedure}

The procedure of this study was approved by the Child Subjects Committee of the Max Planck Institute for Evolutionary Anthropology. The study took place in quiet rooms of nurseries in a German city. All sessions were video recorded. For familiarization with the two experimenters (E1, E2), all dyads first played a card game and all but the first 10 dyads (four 3year-old and six 5-year-old dyads), played an additional ball game with E1 and E2. 
In the warm-up trial, E1 showed the two children and E2 the drawings of two characters and introduced each character: "Susie washed her hands before she ate this apple for breakfast"; "Victor did not wash his hands before he ate this sandwich for breakfast". At this point, E2 evaluated Victor's transgression: "He did not wash his hands? That is not okay!" E1 then explained the game: "Both Susie and Victor really like playing with the marbles. But I only have one marble. Now you two [the two children] can decide together, who should get the marble and place the drawing of the character who should not get the marble in this box." We asked children to act on the picture of the transgressor (i.e. placing its picture away in the box) so that children could focus on and talk about the transgressor. E1 further said: "You two should decide together and explain to each other why. If you choose the right character, you will each get a sticker." The reward was introduced to motivate the children to produce reasons about their proposals and discourage them from choosing a character randomly. After the instructions, E1 left the room and E2 guided the decision-making process by asking children questions to elicit justifications for the decision: "What do you think? Who should get the marble? Why do you think that?" At the end of the discussion, E2 always stated the reason for the decision "I think Victor should go to the box, because he did not wash his hands" regardless of whether children produced the reason themselves, to ensure that each dyad heard a relevant justification in the warm-up trial at least once. E2 then asked the children to put the drawing of the transgressor in the box. E1 walked in and gave children one sticker each.

After the warm-up, there were three experimental trials. The children were randomly assigned to the role of either the target child $(\mathrm{T})$ or the naïve child $(\mathrm{N})$ and kept these roles for all experimental trials. At the beginning of each trial, there were two parallel book-reading sessions: one by $\mathrm{E} 1$ with $\mathrm{T}$ inside the room and one by $\mathrm{E} 2$ with $\mathrm{N}$ outside. 
For T, E1 narrated a picture book about a character's transgression. The exact same picture books were used in both conditions; the only difference between the conditions was how E1 narrated the story: In the moral condition an act was narrated as a moral norm violation, for example, stealing another child's toy car by placing it in her own box. In the social rules condition, the very same act was narrated as a violation of a context-specific rule, for example, putting a yellow car in a green box when it must be placed in a yellow box. In both conditions E1 provided the warrants underlying the transgression twice; first stating what must not be done and then what must be done. For instance, in the moral condition E1 said, "In Mia's kindergarten, you must not steal. In Mia's kindergarten, you should give back the things that do not belong to you". In the social rules condition, E1 said, "In Mia's kindergarten, you must not put yellow things in the green box. In Mia's kindergarten, you should put yellow things in the yellow box". In the other two stories, the act of trashing a piece of paper was portrayed as destroying another child's drawing in the moral condition and as trashing scrap paper instead of keeping it in the social rules condition; the act of eating a cake was portrayed as stealing food in the moral condition and as eating cake with hands instead of using cutlery in the social rules condition.

For N, E2 narrated a picture book about a character's neutral act (e.g., a girl drinking juice). These stories were the exactly same in the two conditions. The gender of the transgressor and the neutral character was the same in each trial. After the book-reading sessions E2 asked N to go back inside. E1 then explained the game to both children. She presented the drawings of the two characters from the two stories (the last pages of the picture books) and said, "This is Mia. You [T] know her already, don't you? This is Sophie. You [N] know her already, don't you? They both like playing with the marbles. But I only have one marble. Now you two can decide together, who should get the marble and place the drawing of the character who should 
not get the marble in this box. You two should decide together and explain to each other why. If you choose the right character, you will each get a sticker." Then E1 left the room and only entered when the children made their decision, got distracted or were confused about what to do. Once the children made a decision, E1 walked in and handed them a sticker each, if they chose the right character or said, "Well, this is not the right one, but I am sure you find the right one next time", if they picked the wrong character. The experimenter did not explain why their choice was correct or incorrect to avoid giving further scaffolding. The procedure for the experimental trial was repeated two more times. The order of the stories was counterbalanced. In one trial the characters were male, and in the other two female.

After the third experimental trial, E1 asked T post-test questions to check whether T comprehended the stories. E1 showed the drawing of each transgressor, which was also used in the experimental trials (the final page of each book), in the order of the book reading and asked T: "Can you tell me what happened here?" If the child did not tell the story, E1 tried to elicit the rule that was violated by asking more specific questions: "Can you see what she/he is doing here?" and "Is she/he allowed to do that?" If the child did not mention that the action of the character was "wrong" in any of the three stories, the dyad was excluded from the analysis. We set this drop-out criterion, as children might have forgotten the stories from the earlier trials by the end of the last trial.

\section{Coding}

The children's conversations during the experimental trials were transcribed. For each trial, we coded the children's choice of characters that should not get a marble with the following four options: correct character, wrong character, both characters, or none. Next, we looked at 
whether the target children produced justifications for their proposals. If they did, we identified the following three types, ranked from the most informative to the least:

- Warrants: justifications explaining the rule with normative language (deontic modal verbs "should/ought/must"; e.g., "She must not put the yellow car in the green box")

- Facts: justifications describing the action in a factual manner without normative language (e.g., "She put the car in her own box", "She stole")

- Irrelevant: justifications unrelated to the story (e.g., "She has nicer hair").

When the target child used more than one justification within one trial, the trial received the code of the most informative justification. For instance, if a child provided a fact and a warrant within one trial, this trial only received the code warrant. For the warrants, we further identified whether the children mentioned the "scope" of the rule in their justifications. If they implied that the rule was limited to the transgressor's kindergarten (e.g., "In his kindergarten, one must X"), it was coded as limited scope and the rest were coded as no scope.

A second coder, who was blind to condition and hypotheses, coded a third of the transcripts, three dyads from each age group and condition, for the item choice, justification type, and warrant type. The agreement was $\kappa=1 ; \kappa=.86$; and $\kappa=.89$ respectively.

\section{Results}

Out of 216 trials, children chose the correct character in 179 trials $(83 \%)$; the target children produced justifications for their decisions in 101 trials (47\%); and the target children produced relevant justifications in 78 trials (36\%). These 78 trials involved 20 justifications (11 in the moral condition, 9 in the social rules condition) produced by 14 -year-old dyads and 58 justifications (26 in the moral condition, 32 in the social rules condition) produced by 265 -yearold dyads. As compared to 3-year-olds, 5-year-olds produced more justifications (60\% vs. 33\%) 
and more "relevant" justifications in the form of warrants or facts (89\% vs. $56 \%$ of trials with justifications; see Table 1 for a detailed overview of justification strategies across age groups, condition and stories). The scope of the warrant (the transgressor's kindergarten) was mentioned only by 5 -year-olds in the social rules condition (in $46 \%$ of the warrants uttered by 5 -year-olds in this condition).

Table 1: Distribution of justification strategies by the target child across age groups, conditions and story types (number of dyads)

\begin{tabular}{|c|c|c|c|c|}
\hline Condition & & girl eating a cake & boy trashing paper & girl placing a car \\
\hline Moral & \multicolumn{4}{|c|}{ 3-year-olds } \\
\hline & warrant & $0.00 \% \quad(0)$ & $5.56 \%$ & $0.00 \% \quad(0)$ \\
\hline & fact & $16.67 \%$ & $22.22 \%$ & $16.67 \%$ \\
\hline & superficial & $22.22 \% \quad(4)$ & $16.67 \%$ & $16.67 \%$ \\
\hline & none & $61.11 \%(11)$ & $55.56 \%(10)$ & $66.67 \%(12)$ \\
\hline \multicolumn{5}{|l|}{ Social rules } \\
\hline & warrant & $5.56 \%$ & $5.56 \%$ & $16.67 \% \quad(3)$ \\
\hline & fact & $0.00 \% \quad(0)$ & $11.11 \% \quad(2)$ & $11.11 \% \quad(2)$ \\
\hline & superficial & $16.67 \% \quad(3)$ & $16.67 \%$ & $0.00 \% \quad(0)$ \\
\hline & none & $77.78 \%(14)$ & $66.67 \%(12)$ & $72.22 \%(13)$ \\
\hline & \multicolumn{4}{|c|}{ 5-year-olds } \\
\hline \multicolumn{5}{|l|}{ Moral } \\
\hline & warrant & $0.00 \% \quad(0)$ & $0.00 \% \quad(0)$ & $5.56 \% \quad(1)$ \\
\hline & fact & $61.11 \%(11)$ & $22.22 \%$ & $55.56 \%(10)$ \\
\hline & superficial & $5.56 \%$ & $11.11 \% \quad(2)$ & $0.00 \% \quad(0)$ \\
\hline & none & $33.33 \% \quad(6)$ & $66.67 \%(12)$ & $38.89 \% \quad(7)$ \\
\hline \multicolumn{5}{|l|}{ Social rules } \\
\hline & warrant & $38.89 \% \quad(7)$ & $38.89 \% \quad(7)$ & $55.56 \%(10)$ \\
\hline & fact & $27.78 \% \quad(5)$ & $5.56 \%$ & $11.11 \% \quad(2)$ \\
\hline & superficial & $5.56 \%$ & $11.11 \% \quad(2)$ & $5.56 \%$ \\
\hline & none & $27.78 \% \quad(5)$ & $44.44 \% \quad(8)$ & $27.78 \% \quad(5)$ \\
\hline
\end{tabular}

We ran three analyses. First, we analyzed what factors influenced children's production of relevant justifications, using Generalized Linear Mixed Model (GLMM) with binomial error 
distribution on the whole data set. We used GLMM because our unit of analysis was each trial and our response variable was a binary measure of whether the children provided a relevant justification (a warrant or a fact) vs. not. Since we had three observations from each dyad (one in each of the three trials), we had the dyad as a random factor such that children's production of justifications in three different trials could reveal clustered/grouped observations. Thus, a GLMM was the most straightforward analysis to account for such data with random factors. The full model included the predictors: age group (3 vs. 5), condition (moral vs. social rules), gender (female vs. male), the trial order (1-3), story (placing car, eating cake, trashing paper) and the random factor of dyad. To test the significance of the full model we compared its fit with a null model, which included the control predictors: gender, trial order, story, and the random factor. The full model improved the fit as compared to the null model $\left(\chi^{2}=17.98, d f=2, p<.001\right)$. Comparison of the full model to the respective reduced models lacking each factor using likelihood ratio tests revealed a significant main effect of age: 5-year-olds produced significantly more relevant justifications than did 3-year-olds $\left(\chi^{2}=17.93, d f=1, p<.001\right)$. It further revealed a main effect of story $\left(\chi^{2}=7.03, d f=2, p=.030\right)$. After hearing the story about trashing paper, children were less likely to produce relevant justifications than after hearing about placing a car into a box $(z=2.43, p=.015)$ or eating cake $(z=1.65, p=.098)$. The latter two stories were not different from each other in this regard $(z=.89, p=.375)$. There was no effect of condition $\left(\chi^{2}=\right.$ $0.09, d f=1, p=.769)$, gender $\left(\chi^{2}=1.19, d f=1, p=.275\right)$, or trial order $\left(\chi^{2}=0.97, d f=1\right.$, $p=.324)$

Next, we investigated whether the production of relevant justifications influenced the children's choices. The unit of analysis was each trial. The response variable was a binary measure of whether children chose the correct character (i.e. whether they chose the correct or 
both) or the incorrect character (i.e. incorrect or none). The full model included the predictors: justification (relevant justification vs. irrelevant/no justification), age group, condition, gender, trial order, story, and the random factor of dyad. The null model included the predictors: age group, condition, gender, trial order, story and the random factor of dyad. The full model improved the fit as compared to the null model $\left(\chi^{2}=7.92, d f=1, p=.005\right)$. Comparing the full model to the respective reduced models lacking each factor using likelihood ratio tests revealed a significant main effect of justification: in the trials with relevant justifications, children were more likely to choose the correct character $\left(\chi^{2}=7.92, d f=1, p=.005\right)$. We further found a main effect of trial order: children were more likely to choose the correct character in the later trials $\left(\chi^{2}=4.36, d f=1, p=.036\right)$. There was marginally significant age difference showing that 5 -yearolds were more likely to choose the correct character $\left(\chi^{2}=3.4, d f=1, p=.065\right)$. There was no significant effect of condition $\left(\chi^{2}=0.02, d f=1, p=.896\right)$, gender $\left(\chi^{2}=0.002, d f=1, p=.968\right)$, or story $\left(\chi^{2}=4.26, d f=2, p=.119\right)$.

Third, we investigated whether condition and age group had an effect on the type of justifications within the 78 trials in which children produced relevant justifications. Because we were interested in the differences in the way children formulate justifications, we only included the trials with relevant justifications in this analysis. The unit of analysis was each justification. The response variable was a binary measure of whether children produced a warrant or a fact. The full model included the predictors: age group, condition and their interaction, gender, trial order, story, and the random factor of dyad. The null model included the predictors: gender, trial order, story, and the random factor of dyad. The full model improved the fit as compared to the null model $\left(\chi^{2}=33.62, d f=3, p<.001\right)$. Using the likelihood ratio to test for the interaction by way of comparing the full model with a reduced model that lacked the interaction revealed that 
the interaction between age and condition was not significant $\left(\chi^{2}=2.10, d f=1, p=.147\right)$.

Therefore, we dropped this interaction term to get interpretable tests of the main effects. The likelihood ratio tests comparing the model without the interaction term with the respective reduced models lacking each factor revealed a significant main effect of condition: the children produced warrants significantly more in the social rules condition than in the moral condition $\left(\chi^{2}=29.35, d f=1, p<.001\right.$, see Figure 1). It further revealed a main effect of trial order, which suggested that children were more likely to produce warrants in the later trials $\left(\chi^{2}=7.19, d f=1\right.$, $p=.007)$. There was no effect of age $\left(\chi^{2}=1.70, d f=1, p=.192\right)$, story $^{1}\left(\chi^{2}=1.11, d f=2\right.$, $p=.575)$, or gender $\left(\chi^{2}=0.32, d f=1, p=.569\right)$.

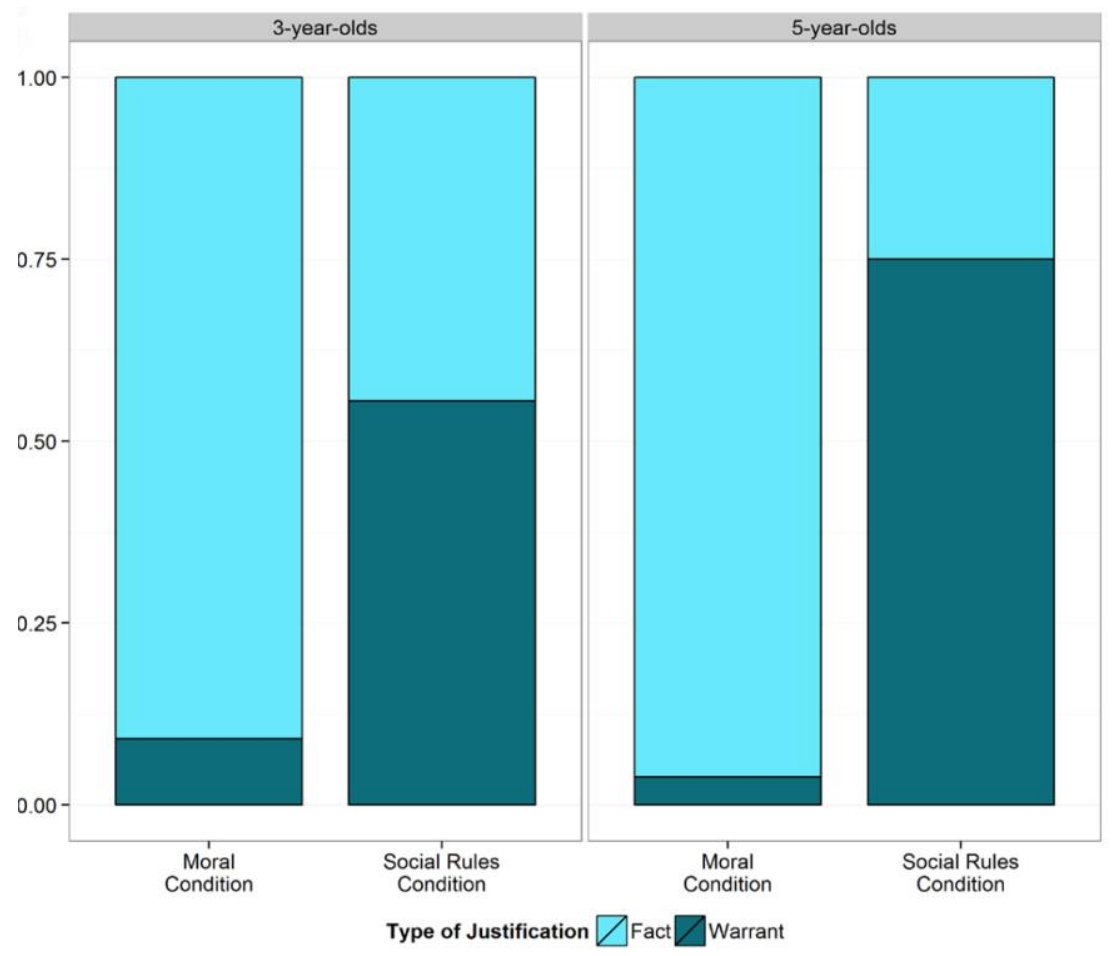

Figure 1: Proportion of justifications

\footnotetext{
${ }^{1}$ We found the same condition difference also when looking at each story individually: children produced significantly more warrants in the social rules condition than in the moral condition for the cake story (Fisher's exact test: $p<.001$ ), for the car story (Fisher's exact test: $p<.001$ ) and for the paper story (Fisher's exact test: $p=.01$ ).
} 


\section{Discussion}

Our results suggest that children of both age groups, although 5-year-olds more consistently, distinguished between moral norms and context-specific social rules when justifying their normative evaluations: they were less likely to explain the rule, or the warrant, when talking about a violation of a moral norm than a violation of a context-specific social rule. In both conditions, we provided the target child with the warrants (e.g., "In this kindergarten, one must not X") during the book reading. However, only in the moral condition, did the children omit some parts of these warrants and relied on factual justifications, presumably because they thought moral norms such as the wrongness of stealing would be part of their cultural common ground. Thus, articulation of this moral norm was not necessary. In the social rules condition, the rule the transgressor violated was limited to the transgressor's kindergarten. In order to convince their naïve peer of the character's wrongdoing, some target children increased the informativeness of their arguments and explicitly mentioned the warrant to potentially justify why such mild transgressions deserve punishment (e.g., "The yellow car must go to the yellow box").

Our results are in line with previous findings that already at preschool age children distinguish between moral norms and social rules. However, unlike the previous studies in the Domain Theory framework in which children were interviewed to evaluate a norm violation (Davidson et al.,1983; Nucci \& Nucci, 1982; Smetana, 1981) or were in a situation where they could directly enforce a rule on a transgressor (Köymen et al., 2015; Schmidt et al., 2012), in the current study, children had to explain a third party's wrongdoing to a peer to justify their proposal for punishing the transgressor. The children in our study did not just reason individually about social norms, but further took their peer's knowledge about the rule as well as some 
inherent features of the rule type into account and adapted the informativeness of their justifications accordingly.

Our findings are also in line with the findings of previous studies on how children flexibly use cultural common ground in their interactions with others (Köymen et al., 2014; Liebal, et al., 2013). Our study extended these findings and showed that children begin to appeal to a special kind of cultural common ground - a moral common ground - in their justifications. In contrast to the previous studies using culturally known figures such as Santa Claus (Liebal et al., 2013) or places such as zoos (Köymen et al., 2014) as part of cultural common ground, our study has shown that preschool children assume more "abstract" common knowledge in their peers such as the severity of breaking a moral norm. However, research also indicates that children's reliance on common ground develops further after preschool ages (Lagattuta, Sayfan, \& Blattman, 2010).

An additional finding was that 5-year-olds were more likely to justify their decisions with relevant justifications (i.e. with warrants or facts) than 3 -year-olds. In $60 \%$ of the trials, 5 -yearolds justified their decisions, while 3-year-olds did so in $33 \%$ of the trials. The task demands of the current study required children to go through several steps: They had to evaluate the severity of the transgression; infer how familiar their peer would be with the kind of transgression observed; and eventually come up with optimally informative justification to convince their partner to reach the correct joint decision to punish the transgressor. Keeping track of all these steps might have been challenging for children of both age groups, especially for 3-year-olds. This, along with other individual factors such as interest in the task, shyness and verbal skills, could explain why a number of children of both age groups, especially 3 -year-olds, did not provide any justifications during the experimental trials, even though it was modeled in the 
warm-up and encouraged by the experimenter. Moreover, the 3-year-olds in our study provided nearly as many irrelevant justifications (e.g., "The color of her dress matches the marble"), as relevant justifications. This is in line with the findings that the ability to decide what constitutes as a good reason develops in preschool period (Bartsch, London, \& Campbell, 2007). However, when children did produce relevant justifications, their justifications differed in terms of informativeness in the two conditions, with the 3-year-olds showing the same pattern as the 5year-olds (see Figure 1).

In the social rules condition, mentioning the limited scope of the rule (the transgressor's kindergarten) would indicate a more sophisticated understanding of the context specificity of social rules: the violated rule does not apply to all children but is limited to a kindergarten. Only a few 5-year-olds showed this more sophisticated normative understanding and stated, for example, "Because in Mia's kindergarten, you must not put yellow cars in the green box, but only in the yellow one." 3-year-olds never mentioned the scope of the context-specific social rule. This indicates again that children begin to show a more nuanced understanding of social norms and their scope during later preschool years. After preschool years, children might be more likely to include the scope of the rule in their justifications for their normative judgments (Horn, 2003; Killen \& Stangor, 2001; Smetana, 2006).

Another finding was that children were more likely to choose the correct character in the trials with relevant justifications than in those with irrelevant or no justifications. This confirms that relevant justifications were what convinced the naïve peer of the correct choice. Further, we did not find a condition difference in the children's choices. This indicates that children's moral judgments-unlike their justifications- were not influenced by the differences of rule familiarity and severity of transgressions between the conditions and they could understand that even 
violating mild transgressions deserve punishment. This also indicates that looking at children's explanations for their normative judgments provides an important window into their normative understanding and their use of common ground. We further found that children were more likely to choose the correct character in the later trials and that they were also more likely to produce warrants in the later trials. The feedback they received at the end of each trial about whether their decision was correct might have led them to be more accurate and more informative in later trials. Further, the story about trashing paper was less likely to elicit relevant justifications than the other two stories, perhaps because trashing a drawing was perceived as a less serious transgression than stealing/misplacing an object. Alternatively, this could be due to this story including more complex language (e.g., use of an infrequent noun phrase "scrap paper") and the picture not showing the blank backside of the picture.

A possible limitation of the current study is that the rules that were violated in the social rules condition might have been less familiar or even unknown to the children as compared to those in the moral condition. Thus, children's use of different explanations in the two conditions could be due to familiarity of the norms (e.g., moral norms are more familiar than social rules so they require less explanation) or due to the severity of the transgressions (e.g., violations of moral norms are more severe than violations of social rules so they require less explanation). The current data does not allow us to disentangle which specific factor drives the differences in children's justifications. One way to overcome this limitation, in theory, would be to match the familiarity of the norms or the severity of the transgressions in both conditions. The problem is that matching moral norms and conventional norms on these dimensions of familiarity and severity may not actually be possible, as these are arguably inherent features of what makes them one type of norm or the other. For instance, even if a social rule is familiar to larger group of 
people (e.g., "one should eat food with a fork"), these rules may still not be treated as familiar as moral norms (e.g., "one should not steal"). Even though we cannot fully disentangle the influence of familiarity and severity on the children's production of justifications, we, nonetheless, showed that children treated moral norms differently than conventional norms in their justifications based on these two inherent features of the two types of rules.

To conclude, justifying moral judgments to a naïve peer to reach a correct joint decision is a complex skill. It requires the speaker to keep track of their moral common ground with the partner based on the type of norm violation they talk about. Our findings confirmed that in preschool ages, children begin to show some sensitivity to the differences between moral norms and social conventions. They assume certain abstract common ground moral values with others and begin to use these in formulating explicit moral judgments. 


\section{References}

Bartsch, K., London, K., \& Campbell, M. D. (2007). Children's attention to beliefs in interactive persuasion tasks. Developmental Psychology, 43(1), 111-120.

http://doi.org/10.1037/0012-1649.43.1.111

Clark, H. H. (1996). Using language. Cambridge University Press.

Davidson, P., Turiel, E., \& Black, A. (1983). The effect of stimulus familiarity on the use of criteria and justifications in children's social reasoning. British Journal of Developmental Psychology, 1(1), 49-65. http://doi.org/10.1111/j.2044-835X.1983.tb00543.x

Gopnik, A., \& Astington, J. W. (1988). Children's understanding of representational change and its relation to the understanding of false belief and the appearance-reality distinction. Child Development, 59(1), 26-37.

Hogrefe, G.-J., Wimmer, H., \& Perner, J. (1986). Ignorance versus false belief: A developmental lag in attribution of epistemic states. Child Development, 57(3), 567. https://doi.org/10.2307/1130337

Horn, S. S. (2003). Adolescents' reasoning about exclusion from social groups. Developmental Psychology, 39, 71-84. doi:10.1037/0012-1649.39.1.71

Ingram, G. P. D., \& Bering, J. M. (2010). Children's tattling: The reporting of everyday norm violations in preschool settings. Child Development, 81(3), 945-957. http://doi.org/10.1111/j.1467-8624.2010.01444.x

Killen, M. (1991). Social and moral development in early childhood. In W. M. Kurtines \& J. L. Gewirtz, Handbook of Moral Behavior and Development (pp. 115-138). Hillsdale, NJ: Erlbaum. 
Killen, M., \& Stangor, C. (2001). Children's social reasoning about inclusion and exclusion in gender and race peer group contexts. Child Development, 72, 174-186. doi:10.1111/1467-8624.00272

Köymen, B., Mammen, M., \& Tomasello, M. (2016). Preschoolers use common ground in their justificatory reasoning with peers. Developmental Psychology, 52(3), 423-429. http://doi.org/10.1037/dev0000089

Köymen, B., Rosenbaum, L., \& Tomasello, M. (2014). Reasoning during joint decision-making by preschool peers. Cognitive Development, 32, 74-85. http://doi.org/10.1016/j.cogdev.2014.09.001

Köymen, B., Schmidt, M. F. H., Rost, L., Lieven, E., \& Tomasello, M. (2015). Teaching versus enforcing game rules in preschoolers' peer interactions. Journal of Experimental Child Psychology, 135, 93-101. http://doi.org/10.1016/j.jecp.2015.02.005

Lagattuta, K. H., Sayfan, L., \& Blattman, A. J. (2010). Forgetting common ground: Six- to seven-year-olds have an overinterpretive theory of mind. Developmental Psychology, 46(6), 1417-1432. https://doi.org/10.1037/a0021062

Liebal, K., Carpenter, M., \& Tomasello, M. (2013). Young children's understanding of cultural common ground. British Journal of Developmental Psychology, 31(1), 88-96. http://doi.org/10.1111/j.2044-835X.2012.02080.x

Nucci, L. P., \& Nucci, M. S. (1982). Children's social interactions in the context of moral and conventional transgressions. Child Development, 53(2), 403-412. http://doi.org/10.2307/1128983

Nucci, L. P., \& Turiel, E. (1978). Social interactions and the development of social concepts in preschool children. Child Development, 49(2), 400-407. http://doi.org/10.2307/1128704 
Mercier, H., \& Sperber, D. (2011). Why do humans reason? Arguments for an argumentative theory. Behavioral and Brain Sciences, 34(2), 57-74.

Schmidt, M. F. H., Rakoczy, H., \& Tomasello, M. (2012). Young children enforce social norms selectively depending on the violator's group affiliation. Cognition, 124(3), 325-333. http://doi.org/10.1016/j.cognition.2012.06.004

Smetana, J. G. (1981). Preschool children's conceptions of moral and social rules. Child Development, 52(4), 1333-1336. http://doi.org/10.2307/1129527

Smetana, J. G. (2006). Social-cognitive domain theory: Consistencies and variations in children's moral and social judgments. In M. Killen \& J. Smetana (Eds.), Handbook of moral development (pp. 119-153). Mahwah, NJ: Erlbaum.

Smetana, J. G., \& Braeges, J. L. (1990). The development of toddlers' moral and conventional judgments. Merrill-Palmer Quarterly, 36, 329-346.

Tomasello, M. (2014). A natural history of human thinking. Harvard University Press.

Toulmin, S. (1958). The uses of argument. Cambridge: Cambridge University Press.

Turiel, E. (1983). The development of social knowledge: Morality and convention. Cambridge: Cambridge University Press.

Vaish, A., Missana, M., \& Tomasello, M. (2011). Three-year-old children intervene in thirdparty moral transgressions. British Journal of Developmental Psychology, 29(1), 124130. http://doi.org/10.1348/026151010X532888

Wellman, H. M., \& Liu, D. (2004). Scaling of Theory-of-Mind Tasks. Child Development, 75(2), 523-541. https://doi.org/10.1111/j.1467-8624.2004.00691.x 


\section{Appendix: The picture books and narratives}

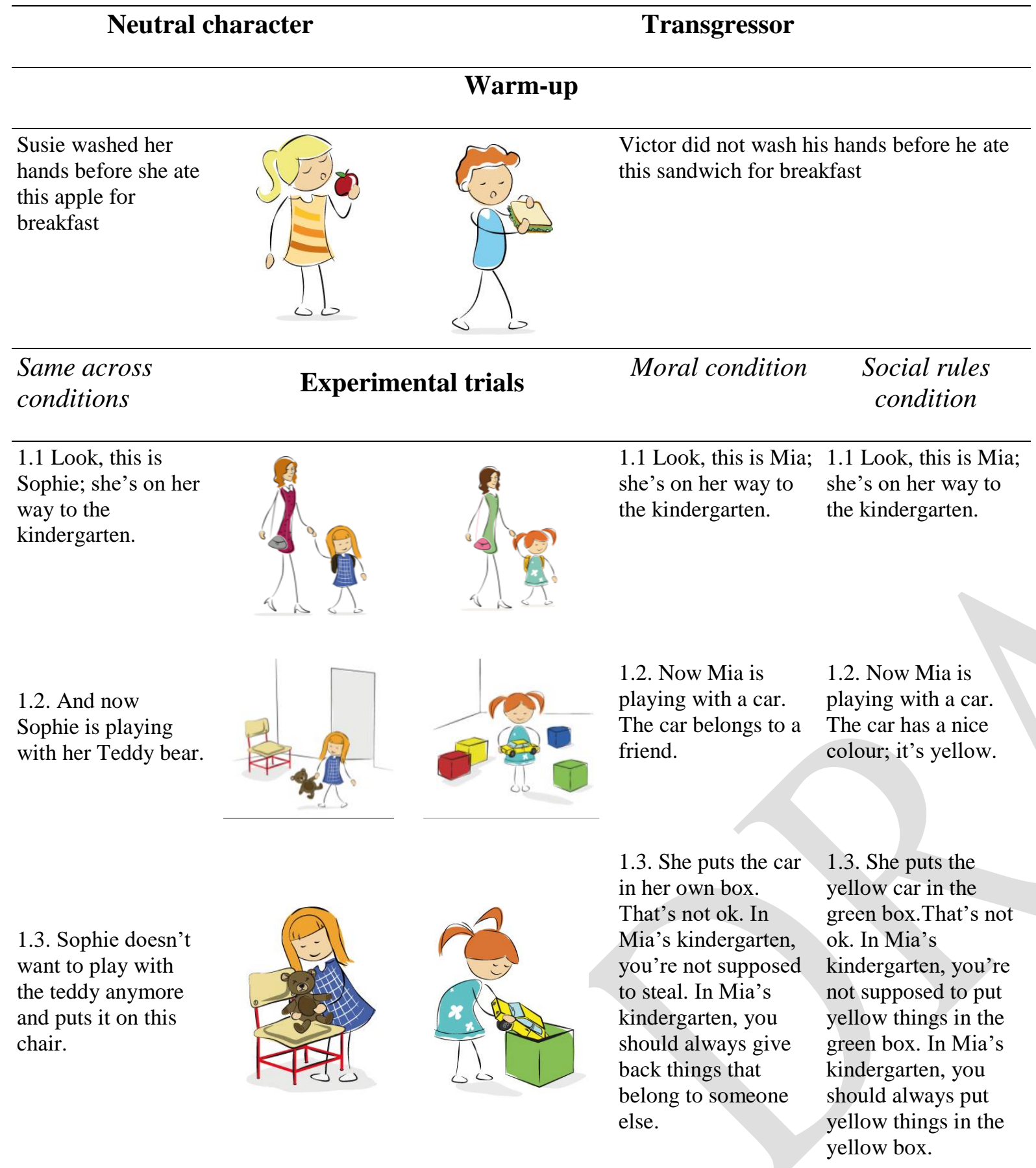


2.1. Look, this is Ben; he's on his way to the kindergarten.

2.2 Today, Ben
brought a book.
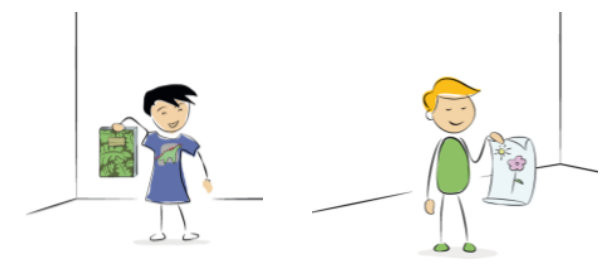

2.2. Now he's looking at a picture one of his friends

2.1. Look, this is 2.1. Look, this is

Tom; he's on his way Tom; he's on his way to the kindergarten. to the kindergarten. drew.

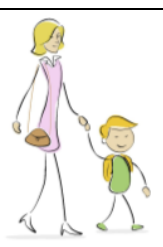

2.2. Now he's looking at a piece of paper that is blank on one side.
2.3. Now he's sitting there and looks at his book.

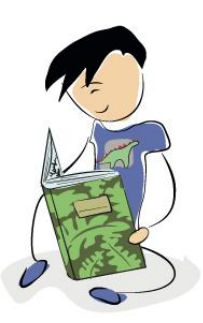

2.3. He's ripping the 2.3. He's throwing drawing apart. That's away the blank paper. not ok. In Tom's That's not ok. In kindergarten, you're Tom's kindergarten, not supposed to break you're not supposed someone else's to throw away paper. things. In Tom's In Tom's kindergarten, you kindergarten, you should always take should always use care of someone blank paper as scrap else's things. paper.

\subsection{Look, this is} Hannah; she's on her way to the kindergarten.

\subsection{It's breakfast time. On the table there is Hannah's bottle of juice.}

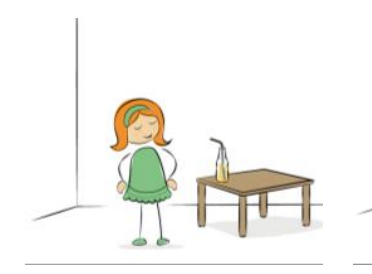

3.3. Now Hannah is drinking her juice.

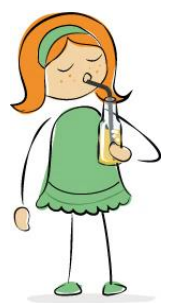

3.1. Look, this is Lisa; she's on her way to the kindergarten.

\subsection{Look, this is} Lisa; she's on her way to the kindergarten.
3.2. It's snack time 3.2. It's snack time and there on the table and there on the table is a piece of cake. It's is a piece of cake. It's some else's cake.

Lisa's cake
3.3. She's eating the cake. That's not ok. In Lisa's kindergarten, you're not supposed to steal someone else's food. In Lisa's kindergarten, you should always leave food that isn't yours.
3.3 She's eating the cake with her hands. That's not ok. In Lisa's kindergarten, you're not supposed to eat with your hands. In Lisa's kindergarten, you should always use a fork for eating your food. 